\title{
ANALISIS KNOWLEDGE MANAGEMENT SYSTEM READINESS DI UNIVERSITAS AMIKOM PURWOKERTO BERDASARKAN ASPEK PEOPLE, PROCESS, TECHNOLOGY
}

\author{
${ }^{1}$ Puji Ratwiyanti, ${ }^{2}$ Yusyida Munsaidah, ${ }^{3}$ Ratna Dewi \\ ${ }^{1}$ Sistem Informasi, Ilmu Komputer, Universitas Amikom Purwokerto, \\ ${ }^{2}$ Teknik Informatika, Ilmu Komputer, Universitas Amikom Purwokerto, \\ ${ }^{3}$ Sistem Informasi, Ilmu Komputer, Universitas Amikom Purwokerto, \\ Email: ratwiyanti@amikompurwokerto.ac.id,yysyida_mi@amikompurwokerto.ac.id, \\ ratnadewiku22@gmail.com
}

(Diterima: 2 November 2019,direvisi: 4 Desember 2019,disetujui: 11 Desember 2019)

\begin{abstract}
Knowledge Management System Implementation consists of diverse and complex aspects. Suitability of Infrastructure and the level of organizational readiness is the key to reach the success of Knowledge Management System Implementation. The aim of this research was to measure the implementation of Knowledge Management system readiness and give advice and input to Amikom Purwokerto University regarding some improvements in the preparation of Knowledge Management System implementation. There were two combinations of indicators to measure the readiness of this system, they were: KMCSF and KM Infrastructure. The Indicators were divided into 3 parts: People, Process and Technology. This research Used Rao Scale 0-5 to interpret the scale of KMS Readiness. The result showed that Amikom Purwokerto University reached 75,06\% from the aspect of KMCSF and KM Infrastructure. It means, in Rao Scale, Amikom Purwokerto University has been reached level 4 (Receptive). Based on this result, it can be concluded that the organization had been ready to implement Knowledge Management System.
\end{abstract}

Keywords: Knowledge Management, Knowledge Management Readiness, Readiness.

\begin{abstract}
ABSTRAK
Implementasi Knowledge Management System mencakup aspek yang beragam dan kompleks. Keberhasilan penerapan Knowledge Management System tidak akan terwujud tanpa adanya kesesuaian antara infrastruktur dan tingkat kesiapan Organisasi. Penelitian ini bertujuan untuk Mengukur tingkat kesiapan penerapan Knowledge Management System di Universitas Amikom Purwokerto serta Memberikan saran dan masukan bagi Universitas Amikom Purwokerto mengenai Aspek yang harus ditingkatkan dalam rangka persiapan implementasi Knowledge Management System Metode yang digunakan adalah menggabungkan faktor pada KMCSF, dan KM Infrastruktur lalu dikelompokan berdasarkan 3 aspek yaitu People, Process And Technology. Kesiapan 3 aspek tersebut diukur dengan skala Rao dari 0 - 5 untuk menginterpretasikan kesiapan. Hasil analisis data dapat disimpulkan bahwa KMReadiness telah mencapai 75,06\%. Angka ini menunjukkan bahwa Universitas Amikom Purwokerto berada di level 4, yang berarti Universitas Amikom Purwokerto mendapat predikat Receptive. Hal ini menunjukkan bahwa Universitas Amikom Purwokerto telah siap dan mapan untuk menerapkan Knowledge Management System.
\end{abstract}

Kata Kunci: Knowledge Management, Knowledge Management Readiness, Readiness.

\section{PENDAHULUAN}

Knowledge management merupakan pendekatan kolaboratif dan terintegrasi untuk menciptakan, mengambil, mengelola, mengakses, dan menggunakan aset intelektual perusahaan[1]. Knowledge Management System (KMS) adalah Sistem Informasi yang diterapkan untuk mengelola pengetahuan organisasi dengan mendukung dan meningkatkan proses organisasi kreasi pengetahuan, penyimpanan / pengambilan, transfer dan aplikasi [2]. Penerapan Knowledge Management System menjadi hal yang 
penting bagi perusahaan, Pengelolaan pengetahuan yang sukses akan lebih mudah membantu perusahaan dalam mempercepat inovasi, mengurangi kesalahan berulang serta mempercepat tujuan strategis Organisasi.

Implementasi Knowledge Management System mencakup wilayah yang cukup besar dan aspek yang beragam. Keberhasilan penerapan Knowledge Management System tidak akan terwujud tanpa adanyakesesuaian antara infrastruktur dan tingkat kesiapan Organisasi. Daniel Morehead, Direktur British Telecommunications PLC di Reston, menegaskan bahwa tingkat kegagalan dalam percobaan penerapan Knowledge Management System bisa mencapai 70\%[3]. Kegagalan yang sering terjadi disebabkan karena implementasi sistem hanya berdasarkan teori - teori saja dan tidak mepertimbangkan keadaan organisasi[4]. Selain itu, kegagalan tersebut terjadi diantaranya karena strategi penerapan KM hanya mementingkan faktor IT saja, kurangnya peran serta pengguna dalam mendesain tools KM, serta keengganan individu di dalam organisasi untuk membagi pengetahuan yang mereka miliki demi kepentingan organisasi[5]. Maka perlu ada aspek lain yang diukur selain aspek TI, dalam hal ini Aspek lain yang bersentuhan langsung dengan $K M S$ juga perlu diukur kesiapannya, yaitu People dan Processs yang benar - benar sesuai dengan kondisi organisasi

Universitas Amikom Purwokerto adalah merupakan salah satu perguruan tinggi swasta dengan visi "Unggul Dalam Pengembangan Ilmu Pengetahuan Dan Teknologi Dengan Menyiapkan SDM Berkualitas Dan Berjiwa Technopreneur Di Tahun 2019". Saat ini Universitas Amikom Purwokerto memiliki 142 orang yang menempati 13 bidang yang berbeda dengan berbagai pengetahuan yang ada di dalam diri masing - masing individu. Universitas Amikom memiliki rencana untuk menerapkan knowledge managementsystem. Adanya rencana penerapan knowledge management system diinisiasi dengan adanya arahan dari pimpinan untuk mulai mendokumentasikan Organizational Stories serta Best Practices dalam organisasi melalui Lembaga Penjaminan Mutu, selain itu Universitas Amikom Purwokerto telah mengadakan studi banding ke perguruan tinggi yang mulai menerapkan knowledge management seperti Universitas Negeri Semarang dan Universitas Amikom Yogyakarta. Nantinya pengembangan portal web dosen dan karyawan sangat memungkinkan menjadi teknologi pendukung dalam penerapan Knowledge ManagementSystem.

Dalam rangka mendukung keberhasilan Implementasi Knowledge Management System Maka ini peneliti akan menganalisis tingkat kesiapan Universitas Amikom Purwokertodalam implementasi knowledge management system dengan mengambil judul "Pengukuran Kesiapan ImplementasiKnowledge Management System Di Universitas Amikom Purwokerto Berdasarkan Aspek People, Process and Technology”.

\section{TINJAUAN PUSTAKA}

\subsection{Knowledge Management Critical Success Factor}

Di dalam bukunya yang berjudul "Knowledge Management Toolkit" Tiwana menyebutkan ada 24 pembelajaran CSF, pada referensi lain David Skryme menyebutkan ada 10 Faktor KMCSF [6]

\subsection{Infrastruktur Knowledge Management}

KM solution adalah upaya untuk memfasilitasi proses KM yang meliputi proses pencarian (discovery), menangkap (capture), mendistribusikan (sharing), dan mengaplikasikan (applicatioan) dari pengetahuan dalam organisasi. Termasuk didalam KM solution adalah KM process dan KM systems. KM solution sangat bergantung kepada KM foundation. Sedangakan bagian dari KM foundation terdapat infrastruktur - infrastruktur Knowledge Management mencakup lima komponen utama, yaitu : Budaya Organisasi, Struktur Organisasi, Infrastruktur Teknologi Informasi, Pengetahuan Umum, Physical Environment/Lingkungan Fisik [5]

\subsection{Knowledge Management System Readiness}

Knowledge Management System juga dapat diartikan sebagai sikap reseptif dari suatu anggota organisasi untuk terlibat dalam proses KM melalui kemampuan sumber daya [7]. Menerapkan KM pada suatu organisasi membutuhkan perubahan yang signifikan dalam organisasi tersebut, dan karena sulitnya untuk memulai suatu perubahan maka terlebih dahulu perlu dilakukan sejumlah persiapan. Sementara itu KM readiness juga didefinisikan sebagai level minimum dari KMMaturity sebelum KM 
dapat diterapkan dalam sebuah organisasi [1]. Level kesiapan dari knowledge management dibagi menjadi menjadi lima level, yaitu [8] :
a. Not Ready,
b. Preliminiary,
c. Ready,
d. Receptive,
e. Optimal.

Penentuan level KM Readiness dilihat dari rata-rata presentase kesiapan suatu organisasi dalam menerapkan knowledge management . presentase kesiapam KM Readiness dihitung dari jumlah angka atau skor masing - masing indikator dibagi total keseluruhan bobot maksimal. Penentuan level tersebut dianalisis dengan menggunakan kuantitatif deskriptif dengan Gambar 1. Presentase Kesiapan KM dibawah ini :

$$
\mathrm{P}=\frac{S n}{S m} \times 100 \%
$$

Keterangan :

\section{Gambar 1 Presentase kesiapan $\mathrm{km}$}

$P$ : merupakan persentase level

Sn : merupakan jumlah nilai dikali bobot yang didapatkan

Sm : merupakan total nilai dikali bobot maksimal

Aspek yang dinilai dari data, kemudian ditabulasi dan diberi skor menggunakan skala penilaian kuantitatif deskriptif. Hasilnya dikonverensi menjadi beberapa nilai yang dapat dilihat pada Gambar 2 Level KM Readiness :

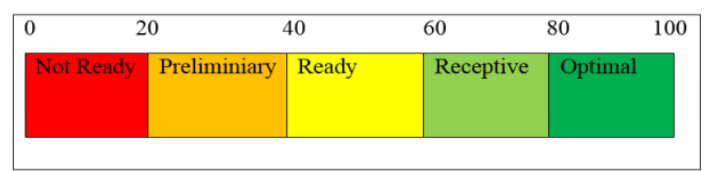

Gambar 2 Level $K M$ readiness[8]

Kelima level diatas dapat dijelaskan sebagai berikut :

$0 \%-20 \%=$ Not Ready

$21 \%-40 \%=$ Preliminiary

$41 \%-60 \%=$ Ready

$61 \%-80 \%=$ Receptive

$81 \%-100 \%=$ Optimal

\subsection{Penelitian Sebelumnya}

Dalam penelitian berjudul Analisis Pengukuran Tingkat Kesiapan Knowledge Management Studi Kasus Pusat Pengolahan Data dan Informasi Badan Koordinasi Penanaman Modal [9]. Penelitian ini menggunakan faktor pata KMCSF yang dipetakan. Hasil dari penelitian ini secara umum, tingkat kesiapan implementasi $K M$ di Pusdatin berada pada kategori tinggi. Hal ini berarti, secara umum, unit Pusdatin telah memiliki kemampuan yang memadai, dan karenanya, matang dalam kesiapannya untuk implementasi KM. Tingkat kesiapan paling tinggi adalah faktor individu, sedangkan tingkat kesiapan yang paling rendah adalah faktor struktur organisasi, dengan penyumbang nilai rendah adalah variabel penghargaan.

Dalam Penelitian dengan judulCritical Success Factors Of Knowledge Management In Albania Business[10]. Metode pepenelitian adalah Kualitatif dengan pemetaan terhadap KMCSF dari hasil studi literature. Hasil dari penelitian ini menunjukkan bahwa faktor kepemimpinan dan dukungan manajemen puncak dan budaya organisasi faktor dianggap sebagai faktor yang paling penting, sedangkan sistem pengukuran dan struktur organisasi yang paling sedikit.

Dalam Penelitian berjudul Knowledge management system implementation readiness measurement in PDII LIPI based on people and organizational structure factors [11]. Yang dihitung Puji Ratwiyanti, Knowledge Management Systemreadiness Di Universitas Amikom Purwokerto Berdasarkan Aspek People, Process, Technology 
pada penelitian ini adalah tingkat kesiapan implementasi $K M S$ pad PDII LIPI yang dibagi berdasar konsep People dan Organizational Structure. Untuk pembobotan kualitas dibantu dengan bantuan kuisioner dan proses hirarki analitikSkala yang digunakan untuk mengintrepretasikan KMS Readiness adalah Aydin dan Tasci Scales. Luaran dari penelitian ini akan digunakan untuk mengevaluasi dan memberikan rekomendasi bagi PDII LIPI untuk mengimplementasikan KMS. Dari pemrosesan kuesioner, skor People and organization structure adalah 3,272 dan 2,818 sehingga kesimpulan untuk kedua faktor berada pada level 'tidak siap membutuhkan pekerjaan'. Dari proses hierarki analitik, bobot prioritas konsep kesiapan implementasi sistem manajemen pengetahuan diekstraksi. Konsep orang $(84,6 \%)$ lebih penting daripada struktur organisasi $(15,4 \%)$

Dalam Penelitian berjudul.Measurement The Level Of The Knowledge Management System Implementation On People, Structure, Culture And Technology Using Analiytical Hierarchy Process (AHP) Method At Telkom University[12]. Penelitian dilakukan dalam dua tahap. Tahap pertama menggunakan $A H P$, fungsinya melihat bobot prioritas indikator sistem manajemen pengetahuan. Tahap kedua adalah menerapkan sistem manajemen pengetahuan yang diukur dengan skala Aydin dan Tasci. Berdasarkan pengukuran menunjukkan bahwa indikator yang digunakan untuk mengukur cenderung berdampak tinggi, ini berarti kesiapan indikator yang digunakan memiliki dampak yang besar. jika tidak diimplementasikan. Penelitian ini menghasilkan urutan prioritas sebagai budaya, teknologi, orang dan struktur. Skala Aydin dan Tasci menyimpulkan bahwa Telkom University berada pada kategori kedua, yang berarti belum siap dan masih perlu beberapa perbaikan.

Dalam penelitian berjudul Assessing The Organizational Readiness For Implementing Knowledge Management In Organizations[13]. Penelitian ini menggunakan enam faktor budaya organisasi, individu, infrastruktur teknologi informasi, proses pengetahuan, komitmen manajemen senior, dan strategi diekstraksi dan telah diuji di tiga organisasi yang berbeda. layanan TI, pendidikan dan perdagangan. Kesimpulan dari penelitian ini, faktor-faktor yang berbeda mempengaruhi berbagai organisasi dan tidak disarankan menggunakan model umum.

Penelitian ini akan mengukur tingkat kesiapan Universitas Amikom Purwokerto dalam mengimplementasi Knowledge Management System. Pustaka diatas membahas tentang berbagai macam metode serta variasi indikator untuk dapat menilai kesiapan sebuah organisasi dalam menerapkanKnowledge Management System. Dari Metode dan Indikator yang telah disajikan pada penelitian diatas, penulis mencoba menggunakan variasi Metode dan Indikator yang digunakan disatu penelitian dengan Metode dan Indikator yang digunakan pada penelitian lainnya, sehingga ada keterbaruan indikator, serta aspek penilaian yang lebih lengkap.

\section{METODE PENELITIAN}

Kerangka pemikiran merupakan gambaran logis bagaimana variabel - variabel saling berhubungan. Kerangka pemikiran menjelaskan hubungan antara variabel yang akan diteliti. Tahap Penelitian dapat dilihat pada Gambar 3. Kerangka Penelitian berikut ini :

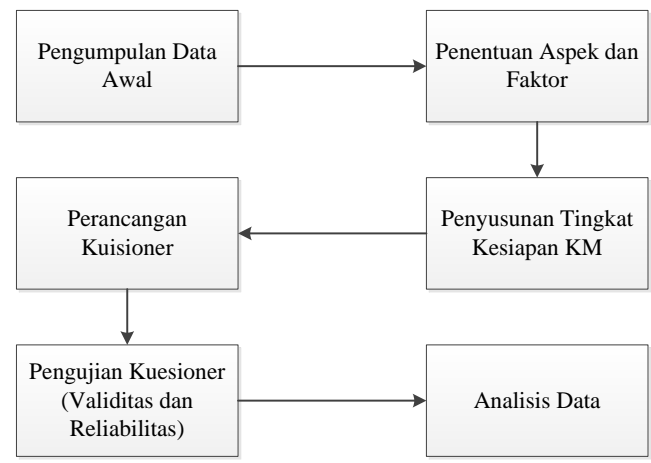

Gambar 3 Kerangka penelitian 


\subsection{Pengumpulan Data Awal}

Pengumpulan data awal dilakukan untuk menentukan topik dan menemukan latar belakang masalah dalam penelitian ini. Teknik pengumpulan data dilakukan dengan cara pengumpulan data primer dan data sekunder. Dari pengumpulan data awal dapat diidentifikasi serta perumusan masalah.. Kemudian langkah selanjutnya yaitu membuat kerangka permasalahan yang dihadapi oleh organisasi yang hendak diteliti sesuai topic yang diangkat.

\subsection{Penentuan aspek dan faktor}

Penentuan aspek dan faktor dilakukan dengan melakukan studi literatur mengumpulkan teori teori terkait topik penelitian. Setelah itu diambil aspek dan faktor yang bisa digunakan dalam penelitian. Penentuan aspek dan faktor didukung dengan proses studi literatur.

\subsection{Penyusunan Tingkatan Tingkat kesiapan KM}

Pada tahap ini penulis menyusun tingkatan Tingkat kesiapan KM yang akan digunakan dalam penelitian ini.

\subsection{Perancangan Kuesioner}

Penyusunan kuesioner disusun berdasarkan instrument - instrument penelitian yang sudah ditentukan sehingga dapat mencapai tujuan yang diharapkan yaitu untuk mengetahui tingkat kesiapan implementasi Knowledge Management di Universitas Amikom Purwokerto.

\subsection{Pengujian Kuisioner}

Pengujian kuesioner dilakukan dengan melakukan uji validitas dan reliabilitas. Pengujian diolah dengan menggunakan software Stastistical Package For Social Science (SPSS) versi 22.

\subsection{Analisis Data}

Dari jawaban responden terhadap kuesioner kesiapan implementasi Knowledge Management pada Universitas AMIKOM Purwokerto, datanya kemudian diolah menggunakan analisis statistic. Analisis dilakukan pada setiap variabel penelitian untuk mendapatkan tingkat kesiapan perusahaan dalam implementasi knowledge managemet system.

\section{HASIL DAN PEMBAHASAN}

\subsection{Pengumpulan Data Awal}

Data primer yang didapat oleh penulis berasal dari wawancara langsung dengan Lembaga Penjaminan Mutu (LPM) Universitas AMIKOM Purwokerto. Data sekunder yang didapat oleh penulis berasal dari studi literatur beberapa penelitian sebelumnya, data lembaga, dan website lembaga.

\subsection{Penentuan Aspek dan Faktor}

Faktor yang dijadikan acuan adalah pada KMCSF dari Tiwana, dan KM Infrastruktur dari BecerraFernandez dan Sabherwal Dimana faktor tersebut dibagi menjadi tiga yaitu kesiapan berdasarkan manusia (People), kesiapan berdasarkan mekanisme (Process) dan kesiapan berdasarkan infrastruktur teknologi (Technology)

\subsection{Penyusunan Tingkatan Tingkat kesiapan KM}

Tingkat kesiapan KM yang dipakai dalam penelitian ini adalah tingkatan Tingkat kesiapan KM dari Rao (2005) yang terdiri dari 5 level yaitu Not Ready, Preliminiary, Ready, Receptive, Optimal.

\subsection{Perancangan Kuesioner}

Instrumen kuesioner didasarkan faktor pada $K M C S F$, dan KM InfrastrukturDimana faktor tersebut dibagi menjadi tiga yaitu kesiapan berdasarkan manusia (People), kesiapan berdasarkan mekanisme (Process) dan kesiapan berdasarkan infrastruktur teknologi (Technology). Untuk mengetahui kesiapan ketiga aspek tersebut maka diukur dengan mengetahui kondisi kesiapan Knowledge Management yang dilakukan oleh Universitas Amikom Purwokerto saat ini (Current Condition)dan diukur pula mengetahui seberapa penting penerapan Knowledge Management System (Future Condition) bagi anggota organisasi. Dari langkah diatas didapatkan 68 butir pernyataan untuk menguji Current 
Condition dan 68 pernyataan untuk menguji Future Condition yang pada akhirnya untuk mengetahui kesiapan penerapan Knowledge Management System berdasarkan manusia (People), kesiapan berdasarkan mekanisme (Process) dan kesiapan berdasarkan infrastruktur teknologi (Technology)

\subsection{Pengujian Kuisioner}

Berdasarkan hasil uji validitas diketahui bahwa 68 pernyataan terkait Current Condition(Kondisi kesiapan saat ini) yang diuji dinyatakan valid dengan nilai rata - rata r-hitung 0.695 dari seluruh total pernyataan dengan nilai r-tabel 0.325 . Sedangkan 67 pernyataan terkaitFuture Condition(kepentingan bagi masa depan organisasi) dinyatakan valid dengan nilai r-hitung 0.203 yaitu lebih kecil atau $\leq 0.325$. Terdapat 67 pernyataan valid dengan nilai rata - rata r-hitung 0.698 dari seluruh total pernyataan dengan nilai r-tabel 0.325 .

Berdasarkan Uji reliabilitas yang dilakukan diperoleh hasil reliabel pada aspek People, Process and Technology. Pada uji reliabilitas Current Condition(kondisi kesiapan saat ini) dinyatakan reliabel karena nilai dengan rata - rata nilai crondbach alpha 0.871 dari total aspek. Pada uji reliabilitas Future Condition(kepentingan bagi masa depan organisasi). reliabel karena nilai dengan rata - rata nilai crondbact alpha 0.859 dari total aspek.

\subsection{Analisis Data}

\section{Current Condition}

Nilai rata - ratakondisi terkinidari kesiapan $K M($ Current Condition)yang telah dihitung dari 37 responden mendapatkan nilai sebesar 75,06\% atau pada level 4 (Receptive), untuk detail presentase dapat dilihat pada tabel 4.5 di bawah. Berdasarkan Knowledge Management Readiness Level yang dijelaskan pada Tabel 1.

Tabel 1 Hasil Perhitungan Current Condition

\begin{tabular}{|c|c|c|c|c|c|}
\hline Aspek & Komponen & $\begin{array}{c}\text { Rata - } \\
\text { Rata } \\
\text { Kesiapan } \\
\text { Komponen } \\
\end{array}$ & $\begin{array}{c}\text { Tingkat } \\
\text { Kesiapan } \\
\text { Aspek }\end{array}$ & $\begin{array}{c}\text { Rata-Rata } \\
\text { Kesiapan } \\
\text { Aspek }\end{array}$ & $\begin{array}{c}\text { Rata-Rata } \\
\text { Kesiapan } \\
\text { Keseluruhan }\end{array}$ \\
\hline \multirow{3}{*}{ People } & $\begin{array}{c}\text { Pemahaman } \\
\text { mengenai } \\
\text { Knowledge } \\
\text { Management }\end{array}$ & $71.69 \%$ & 4 & \multirow{3}{*}{$75.62 \%$} & \multirow{15}{*}{$75.06 \%$} \\
\hline & $\begin{array}{c}\text { Inisiatip } \\
\text { Penerapan } \\
\text { Knowledge } \\
\text { Management }\end{array}$ & $81.34 \%$ & 5 & & \\
\hline & People Skills & $77.16 \%$ & 4 & & \\
\hline \multirow{9}{*}{ Process } & Leadership & $76.88 \%$ & 4 & \multirow{9}{*}{$75.96 \%$} & \\
\hline & Organization & $73.25 \%$ & 4 & & \\
\hline & Culture & $68.23 \%$ & 4 & & \\
\hline & Processess & $76.69 \%$ & 4 & & \\
\hline & $\begin{array}{c}\text { Explicit } \\
\text { Knowledge }\end{array}$ & $69.46 \%$ & 4 & & \\
\hline & $\begin{array}{c}\text { Tacit } \\
\text { Knowledge }\end{array}$ & $80.81 \%$ & 5 & & \\
\hline & Measure & $80.36 \%$ & 5 & & \\
\hline & Exploitation & $77.84 \%$ & 4 & & \\
\hline & Learning & $78.92 \%$ & 4 & & \\
\hline \multirow{3}{*}{ Technology } & $\begin{array}{l}\text { Knowledge } \\
\text { Hub And } \\
\text { Center }\end{array}$ & 65.41 & 4 & \multirow{3}{*}{$72.69 \%$} & \\
\hline & $\begin{array}{c}\text { Technology } \\
\text { Infrastructure }\end{array}$ & 75.19 & 4 & & \\
\hline & $\begin{array}{c}\text { Physical } \\
\text { Environment }\end{array}$ & 77.48 & 4 & & \\
\hline
\end{tabular}

(Sumber: Pengolahan Data)

\section{Future Condition}


Nilai rata - rata harapan kesiapan(Future Condition)dari ketiga aspek yang telah dihitung dari 37 responden mendapatkan nilai sebesar $85,63 \%$ atau pada level 5 (Optimal), untuk detail presentase dapat dilihat pada Tabel 2 di bawah.

Tabel 2 Hasil Perhitungan Future Condition

\begin{tabular}{|c|c|c|c|c|c|}
\hline Aspek & Komponen & $\begin{array}{c}\text { Rata - } \\
\text { Rata } \\
\text { Harapan } \\
\text { Kesiapan }\end{array}$ & $\begin{array}{c}\text { Tingkat } \\
\text { Harapan } \\
\text { Kesiapan }\end{array}$ & $\begin{array}{c}\text { Rata-Rata } \\
\text { Harapan } \\
\text { Kesiapan } \\
\text { Aspek }\end{array}$ & $\begin{array}{c}\text { Rata-Rata } \\
\text { Harapan } \\
\text { Kesiapan } \\
\text { Keseluruhan }\end{array}$ \\
\hline \multirow{3}{*}{ People } & $\begin{array}{c}\text { Pemahaman } \\
\text { mengenai } \\
\text { Knowledge } \\
\text { Management }\end{array}$ & $87,84 \%$ & 5 & \multirow{3}{*}{$84,36 \%$} & \multirow{15}{*}{$85,63 \%$} \\
\hline & $\begin{array}{c}\text { Inisiatip } \\
\text { Penerapan } \\
\text { Knowledge } \\
\text { Management }\end{array}$ & $88,10 \%$ & 5 & & \\
\hline & People Skills & $77,16 \%$ & 4 & & \\
\hline \multirow{9}{*}{ Process } & Leadership & $88,86 \%$ & 5 & \multirow{9}{*}{$82,9 \%$} & \\
\hline & Organization & $84,87 \%$ & 5 & & \\
\hline & Culture & $69,95 \%$ & 4 & & \\
\hline & Processess & $82,85 \%$ & 5 & & \\
\hline & $\begin{array}{c}\text { Explicit } \\
\text { Knowledge }\end{array}$ & $78,65 \%$ & 4 & & \\
\hline & $\begin{array}{c}\text { Tacit } \\
\text { Knowledge }\end{array}$ & $83,12 \%$ & 5 & & \\
\hline & Measure & $87,40 \%$ & 5 & & \\
\hline & Exploitation & $86,76 \%$ & 5 & & \\
\hline & Learning & $84,33 \%$ & 5 & & \\
\hline \multirow{3}{*}{ Technology } & $\begin{array}{l}\text { Knowledge } \\
\text { Hub And } \\
\text { Center }\end{array}$ & $81,08 \%$ & 5 & \multirow{3}{*}{$85,6 \%$} & \\
\hline & $\begin{array}{c}\text { Technology } \\
\text { Infrastructure }\end{array}$ & $86,73 \%$ & 5 & & \\
\hline & $\begin{array}{c}\text { Physical } \\
\text { Environment }\end{array}$ & $89,19 \%$ & 5 & & \\
\hline
\end{tabular}

(Sumber: Pengolahan Data)

3. Gap Analysis

Analisis Aspek People

Pada Current Condition Aspek People di Universitas Amikom Purwokerto mendapat rata - rata kesiapan aspeknya sebesar 76,52 \%, Kesiapan Knowledge Management System dalam aspek People secara keseluruahan dapat digolongkan ke level 4 (Receptive). Sedangkan Harapan dari kesiapan aspek Peoplerata - ratanya adalah 84,36\% atau digolongkan ke Level 5 (Optimal). Diagram perolehan hasil presentase untuk setiap komponen dalam aspek People dapat dilahat pada Gambar 4. Gap Analysis Aspek People

Dari perolehan Current Condition dan Future Condition dari Aspek People terdapat kesenjangan sebesar 7,84\% dan Universitas Amikom Purwokerto perlu mengejar kesenjangan tersebut agar penerapan Knowledge Management System berjalan lebih maksimal terutama pada People Skills dan Pemahaman Mengenai KM. 


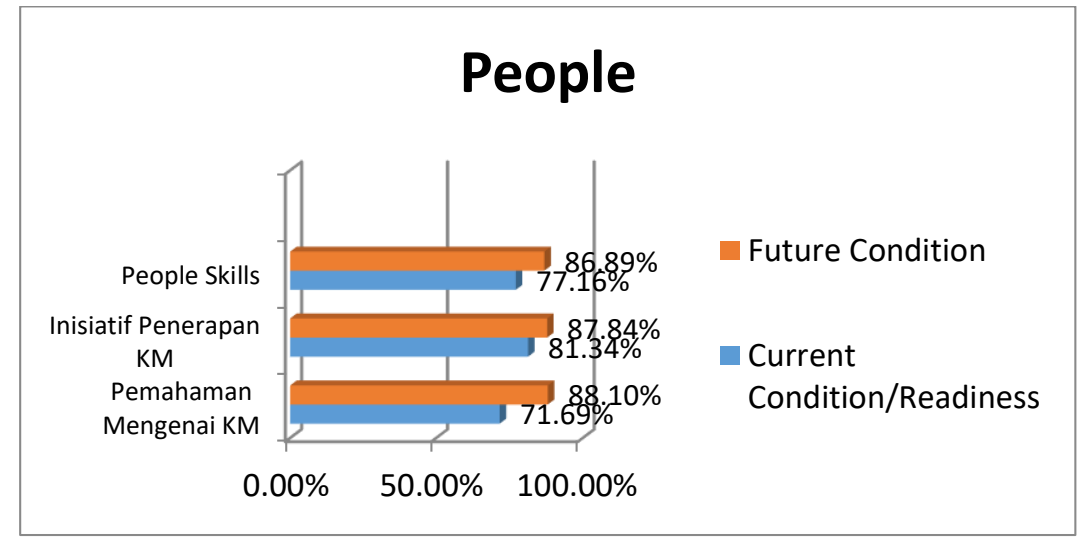

Gambar 4 Gap analysis aspek people

4. Analisis Aspek Process

Pada Current Condition Aspek Process di Universitas Amikom Purwokerto mendapat rata rata kesiapan aspeknya sebesar 75,96 \%, Kesiapan Knowledge Management System dalam aspek Process secara keseluruahan dapat digolongkan ke level 4 (Receptive). Sedangkan Harapan dari kesiapan aspek Processrata - ratanya adalah 82,9\% atau digolongkan ke Level 5 (Optimal). Diagram perolehan hasil presentase untuk setiap komponen dalam aspek Processdapat dilihat pada Gambar 5. Gap Analysis Aspek Process

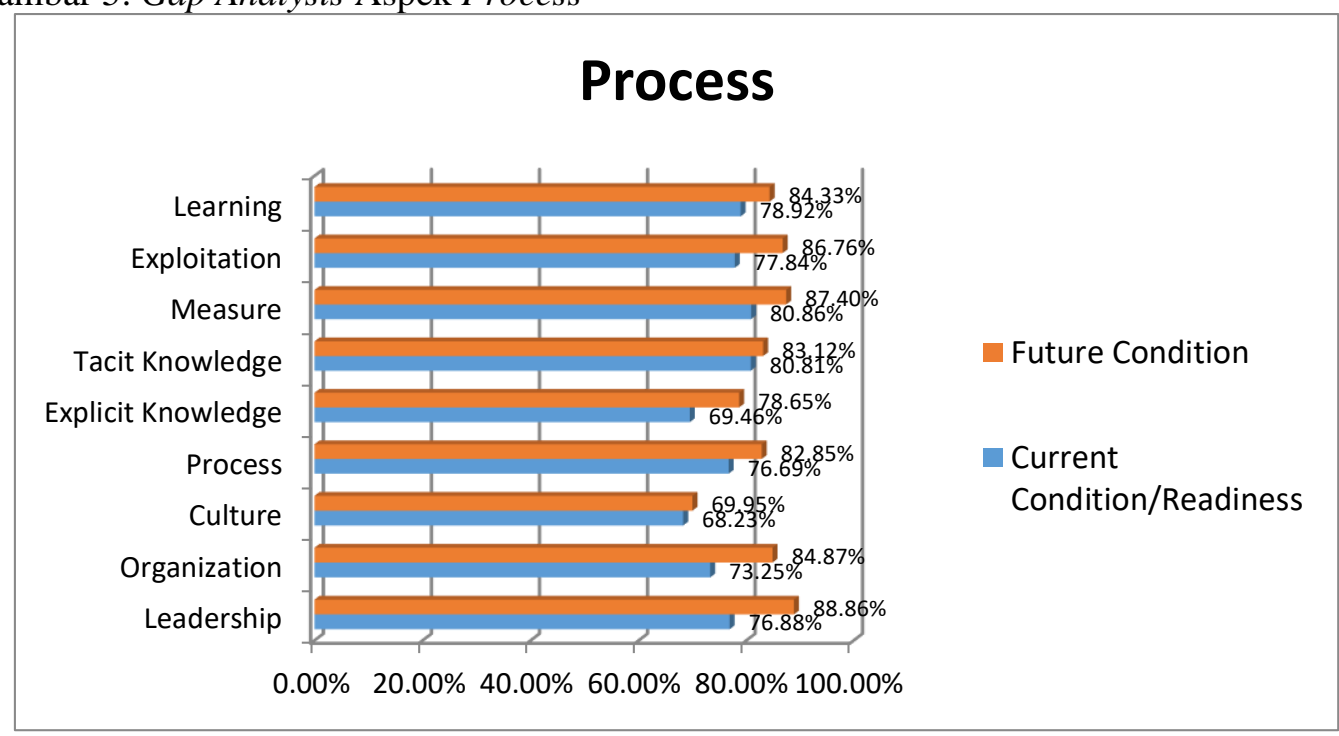

\section{Gambar 5 Gap analysis aspek process}

Dari perolehan Current Condition dan Future Condition dari Aspek Process terdapat kesenjangan sebesar 6,94\% dan Universitas Amikom Purwokerto perlu mengejar kesenjangan tersebut agar penerapan Knowledge Management System berjalan lebih maksimal terutama pada Leadership, Organization, Culture, Explicit Knowledge, Exploitation, Learning.

5. Analisis Aspek Technology

Pada Current Condition Aspek Technology di Universitas Amikom Purwokerto mendapat rata - rata kesiapan aspeknya sebesar 72.69\%, Kesiapan Knowledge Management System dalam aspek Technology secara keseluruahan dapat digolongkan ke level 4 (Receptive). Sedangkan Harapan dari kesiapan aspek Technology rata - ratanya adalah 85,6\% atau digolongkan ke Level 5 (Optimal). Diagram perolehan hasil presentase untuk setiap komponen dalam aspek Technology dapat dilihat pada Gambar 6. Gap Analysis Aspek Technology

Dari perolehan Current Condition dan Future Condition dari Aspek Technology terdapat kesenjangan sebesar 12,91\% dan Universitas Amikom Purwokerto perlu mengejar kesenjangan tersebut agar penerapan Knowledge Management System berjalan lebih maksimal terutama pada Knowledge Hub and Center, Technology Infrastructure, dan Physical Environment. 


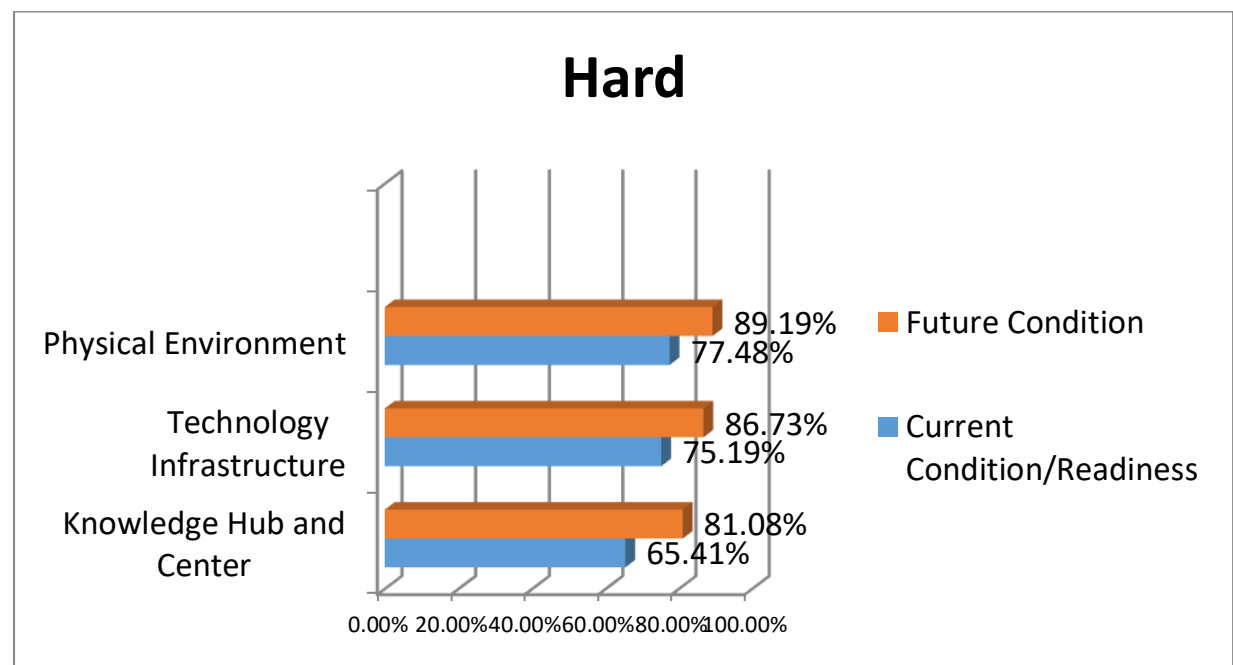

\section{Gambar 6 Gap analysis aspek technology}

\section{KESIMPULAN}

Dengan menggunakan kerangka pengukuran knowledge management readiness level maka diperoleh presentase kesiapan implementasi knowledge management saat ini pada Universitas Amikom Purwokerto adalah sebesar 75,06\% atau Receptive (Level 4). Hal ini berarti organisasi telah siap dan mapan untuk mengimplementasikan knowledge managementsystem. Agar penerapan Knowledge Management System di Universitas Amikom Purwokerto lebih optimal maka diharapkan Universitas Amikom Purwokerto mencapai presentase kesiapan sebesar 85,63\%. Untuk mencapai harapan tersebut perlu dilakukan langkah - langkah perbaikan pada komponen - komponen yang belum mencapai level optimal yaitu Pemahaman mengenai Knowledge Management, Leadership, Organization, Culture, Explicit Knowledge, Exploitation, People Skills, Learning, Knowledge Hub and Center, Technology Infrastructure, dan Physical Environment.

\section{REFERENSI}

[1] K. Dalkir, Knowledge Management in Theory and Practice, 2nd ed. Oxford: Elsevier Inc., 2005.

[2] M. Alavi and D. Leidner, "Knowledge Management Systems: Issues, Challenges, and Benefits," Commun. Assoc. Inf. Syst., vol. 1, no. February, 1999.

[3] Ambrosio, "Failure in the implementation of Knowledge Management System," www.computerworld.com, 2018. [Online]. Available: http://www.computerworld.com/industrytopics/energy/story/0,10801,46693,00.html.

[Accessed: 28-Oct-2018].

[4] D. A. W. Prapto and dan S. Hutagalung, "Tingkat Kesiapan Implementasi Knowledge Management Pada Divisi Teknologi Informasi PT. 'X,'” J. Sist. Inf., vol. 12, no. 2, pp. 95-103, 2016.

[5] I. Becerra-Fernandez and S. RajIv, Knowledge Management Systems and Processes. New York: M.E Sharpe Inc, 2010.

[6] A. Tiwana, Knowledge Management Toolkit, 1st ed. New Jersey: Prentice Hall PTR, 1999.

[7] R. Jalaldeen, N. S. A. Karim, and N. Mohamed, "Organizational readiness and its contributing factors to adopt KM processes: A conceptual model," Innov. Knowl. Manag. Twin Track Econ. Challenges Solut. - Proc. 11th Int. Bus. Inf. Manag. Assoc. Conf. IBIMA 2009, vol. 1-3, no. 2007, pp. 385-393, 2009. 
[8] M. Rao, Knowledge Management Tools and techniques. Oxford: Elsevier.Inc, 2005.

[9] S. Widiastuti and indra Budi, "Analisis Pengukuran Tingkat Kesiapan Knowledge Management: Studi Kasus Pusat Pengolahan Data dan Informasi Badan Koordinasi Penanaman Modal," Semin. Nas. Apl. Teknol. Inf., no. 90, p. 1, 2016.

[10] E. Margilaj and B. Kreshnik, "Critical Sucsess Factors Of Knowledge Management In Alabania Business Organisation,” Eur. J. Res. Reflect. Manag. Sci., vol. 3, no. 2, p. 15, 2015.

[11] S. I. Pradana, A. Kurniawati, and N. Ambarsari, "Knowledge Management System Implementation Readiness Measurement in PDII LIPI Based on People and Organizational Structure Factors," Procedia Manuf., vol. 4, no. January, pp. 216-223, 2015.

[12] A. Nia, A. Yogi, and A. Kurniawati, "Measurement The Level Of The Knowledge Management System Implementation On People, Structure, Culture, And Technology Factor Using Analitycal Hierarchy Process (AHP) Method At Telkom University," Gtar-2015, vol. 2, pp. 706-715, 2015.

[13] S. Shahidi, N. Abdolvand, and S. Rajaee Harandi, "Assessing The Organizational Readiness For Implementing Knowledge Management In Organizations," Int. J. Inf. Technol. Converg. Serv., vol. 5, no. 6, pp. 11-23, 2015. 